\title{
Methodologies to Analyze the Micromorphological Alterations of Enamel Subjected to Abrasion/Erosion
}

\section{Passos VF and Santiago SL*}

Federal University of Ceará, Brazil

*Corresponding author: Prof. Sérgio Lima santiago, Faculty of Pharmacy, Dentistry and Nursing, Federal University of Ceará, Rua Monsenhor Furtado S/N -Rodolfo Teófilo -60430-355, Brazil, Tel: 558533668410; Fax: 558533668232; E-mail: sergiosantiago@yahoo.com

Rec date: Jul 17, 2014, Acc date: Sep 12, 2014, Pub date: Sep 14, 2014

Copyright: ( 2014 Passos VF, et al. This is an open-access article distributed under the terms of the Creative Commons Attribution License, which permits unrestricted use, distribution, and reproduction in any medium, provided the original author and source are credited.

\begin{abstract}
The incidence of caries has declined; however, other dental lesions such as tooth wear are becoming increasingly important. Dental wear is a multifactorial process that may encompass erosion, abrasion, and combinations thereof. Therefore, various methodologies have been applied to evaluate the loss of dental hard tissue and the surface-softened zone in enamel induced by abrasive and erosive challenges. In this review, different techniques to evaluate alterations in enamel are analyzed, such as microhardness, surface profilometry, surface roughness, microradiography, atomic force microscopy (AFM), AFM nanoindentation, scanning electron microscopy, white light interferometer, and confocal laser scanning microscopy. Therefore, the knowledge about these techniques is indispensable in the choice of methods to measure dental wear.
\end{abstract}

Keywords: Enamel; Erosion; Abrasion

\section{Introduction}

Improved oral care, including the use of fluoride toothpastes and an increased oral hygiene of the population, have led to a reduction of the number of caries in industrialized countries. However, this has been followed by the increase in other dental lesions, such as tooth wear [1].

Tooth wear denotes the non-carious destructive processes and is likely to be a multifactorial phenomenon. It is a cumulative lifetime process, which may lead to a substantial tooth surface loss. The term "tooth wear" describes the gradual loss of hard tissue through processes of erosion, attrition, and abrasion [2]. Dental erosion is defined as the chemical dissolution of teeth by acids of non-bacterial origin or chelating. It is caused by acids of either intrinsic or extrinsic origin. The most common intrinsic source of erosive acid is hydrochloric acid produced by the stomach. It is frequently observed in patients with conditions that promote chronic vomiting, such as bulimia, alcoholism, and, to a lesser extent, pregnancy. In the modern society, the extrinsic factors have been more important due to the higher consumption of acids drinks such as soft drinks, juices, sport drinks, and others [3-5]. Exposure of enamel to acid renders it more vulnerable to abrasion. It is well-recognized that a mechanical factor (toothbrush abrasion) has a synergistic effect with erosion. Therefore, interactions between abrasion, erosion, and attrition contribute strongly to visible clinical wear. Many studies have assessed the largest loss of tooth structure by action of erosion and abrasion [6-11]. Therefore, efforts have been made to elucidate how erosive/abrasive lesions can be prevented [12-17].

Evaluating dental wear depends on the correct choice of a method to measure the micromorphological alteration of the dental structure. In the meantime, there are different techniques able to quantify the erosion occasioned by intrinsic and extrinsic acids, the abrasion by oral hygiene substances, and the action of products which can be utilized to prevent or reduce dental structure loss. The techniques can obtain quantitative and qualitative data, determine products that can be harmful to tooth longevity and function, and increase the knowledge of preventive products.

This study critically analyzes the most established as well as new techniques to evaluate dental wear and allows for the understanding that the complex action of erosion/abrasion might not be able to be evaluated by a single analysis.

\section{Data Sources}

"Medline" and "Scopus" databases were searched electronically with the principal key words "tooth", "enamel", "mineral", "abrasion", and "erosion". The language was restricted to English and original studies and reviews were included.

\section{Literature Review}

Different techniques are developed to analyze dental wear (Table 1). In vitro models are extremely useful to demonstrate the erosive capacity of a substance $[9,11,18-28]$, but cannot replicate the oral environment with all its biological variations [29]. In situ studies allow interactions to take place among bacteria, saliva, and hard tissues in the oral environment, while retaining the sensitivity of laboratory analysis [6-8,10,13,15,29-33].

The determination of micromorphological alteration in enamel dental occasioned by erosion or erosion plus abrasion can be assessed using different methods, such as analyses of dental structure by hardness, atomic force microscopy (AFM), microradiography, roughness, scanning electron microscopy (SEM), surface profilometry, and other techniques. 


\begin{tabular}{|c|c|c|c|c|}
\hline Methods & Advantages & Disadvantages & Suitability for early erosion & Type of analysis \\
\hline Microhardness & $\begin{array}{l}\text {-Relatively low costs } \\
\text {-Nondestructive technique }\end{array}$ & - Not evaluate wear & Suitable & Quantitative \\
\hline Surface Profilometry & $\begin{array}{l}\text {-Nondestructive technique } \\
\text {-Evaluate wear } \\
\text { - Not time-consuming }\end{array}$ & $\begin{array}{l}\text { - Perfectly flat and polished } \\
\text { specimens } \\
\text { - Mechanical profilometry } \\
\text { could damage surface }\end{array}$ & Limitedly suitable & Quantitative \\
\hline Surface roughness & $\begin{array}{l}\text { - Evaluate texture } \\
\text { - Not time-consuming }\end{array}$ & - & Suitable & Quantitative \\
\hline Microradiography & $\begin{array}{l}\text {-Evaluate mineral loss and } \\
\text { demineralization }\end{array}$ & - Destructive technique & Not suitable & Quantitative \\
\hline Atomic Force Microscopy and & $\begin{array}{l}\text {-Nondestructive technique } \\
\text { - Very sensitive }\end{array}$ & $\begin{array}{l}\text { - Time-consuming } \\
\text { - Long experience } \\
\text {-High costs }\end{array}$ & Suitable & Qualitative \\
\hline AFM Nanoindentation & $\begin{array}{l}\text {-Allow the measurement of } \\
\text { nanomechanical properties } \\
\text { such as surface hardness } \\
\text { and reduced elastic modulus } \\
\text { - Nondestructive technique }\end{array}$ & \begin{tabular}{|l}
- Time-consuming \\
$-\quad$ Demanding $\quad$ sample \\
preparation
\end{tabular} & Suitable & Quantitative \\
\hline SEM & \begin{tabular}{|r}
- -High resolution \\
- \\
micromorphological alteration
\end{tabular} & $\begin{array}{l}\text {-Destructive technique } \\
\text {-Specimens need be coat with } \\
\text { a conductive layer } \\
\text { - High costs }\end{array}$ & Suitable & Qualitative \\
\hline White Light interferometer & $\begin{array}{l}\text { - Nondestructive technique } \\
\text {-Could evaluate native } \\
\text { surfaces } \\
\text {-Determine roughness and } \\
\text { wear }\end{array}$ & $\begin{array}{l}\text {-Emerging technique } \\
\text {-Long experience }\end{array}$ & Limitedly suitable & Quantitative \\
\hline Confocal Laser Scanning Microscopy & $\begin{array}{l}\text {-High resolution } \\
\text {-Nondestructive technique }\end{array}$ & - Long experience & Suitable & Qualitative \\
\hline
\end{tabular}

Table 1: Survey of the methods described in the text with respect to advantages and disadvantages, suitability for use with erosion (after few minutes of acidic challenge), as well as to type of analysis (quantitative or qualitative)

Some studies use chemical analyses that allow determination of the amount of mineral dissolved from teeth during erosion [20,34]. Nevertheless, no information about the effect of acids on the microstructure of enamel can be obtained with this method [35]. In the following, the techniques most widely utilized to evaluate the microstructural alteration as well as emerging methods will be described.

\section{Microhardness}

The effect of extrinsic and intrinsic acids in dental erosion can be investigated by the microhardness test. This technique can evaluate early stages of enamel and dentin dissolution, which are associated with weakening of the surface [36-39].

In this test, a pyramid shaped fine diamond tip of known geometry is pushed into the enamel or dentin surface with a defined load. This results in an indentation in the surface of the tooth, and the measure of the diameter of the indentation indicates the microhardness, which is measured with a micrometer scale incorporated into the ocular part of the microscope.
The microhardness is the value of resistance of the enamel or dentine against local plastic deformation. Frequently, microhardness methods are the Knoop hardness and the Vickers hardness tests. The difference between these is the shape of the diamond probes. The Knoop diamod results in a rhomboid indentation, while the Vickers' results in a tetra-pyramidal indentation (Figures 1 and 2).

The Knoop microhardness test is more sensitive to surface hardness than many other conventional hardness tests and it is suitable for the measurement materials such as hydroxyapatite, the main component of dental enamel [35].

The formula utilized to convert the indentation length to KHN (Knoop Hardness Numbers) is $\mathrm{KHN}=14.230 \mathrm{x} \mathrm{P} / \mathrm{IL}^{2}$, where $\mathrm{KHN}$ is in $\mathrm{Kg} / \mathrm{mm}^{2}, \mathrm{P}$ is the load in $\mathrm{g}$, IL is the indentation length in micrometers, and 14.230 is a constant utilized to converting grams into kilograms and micrometers into millimeters [40]. Additionally, the formula to VHN (Vickers Hardness Numbers) is $\mathrm{VHN}=1.854$ $\mathrm{Q} / \mathrm{L}^{2}$, where $\mathrm{Q}$ is the load in $\mathrm{kgf}$ and $\mathrm{L}$ is the arithmetic mean of the two diagonals, $d 1$ and $d 2$, in $\mathrm{mm}$ [41]. 


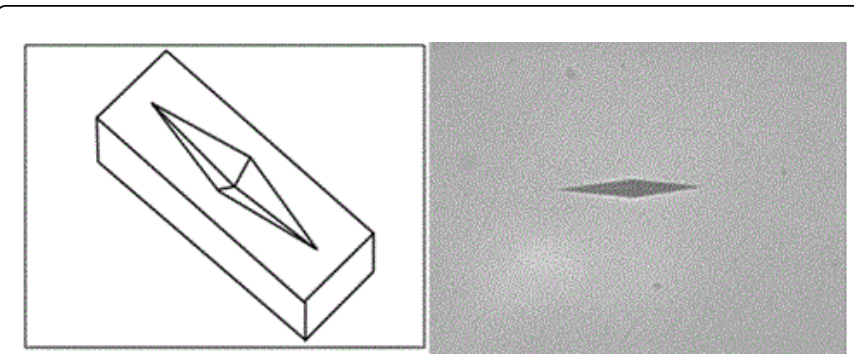

Figure 1: Knoop indentation. A: Schematic image; B: Indentation in enamel

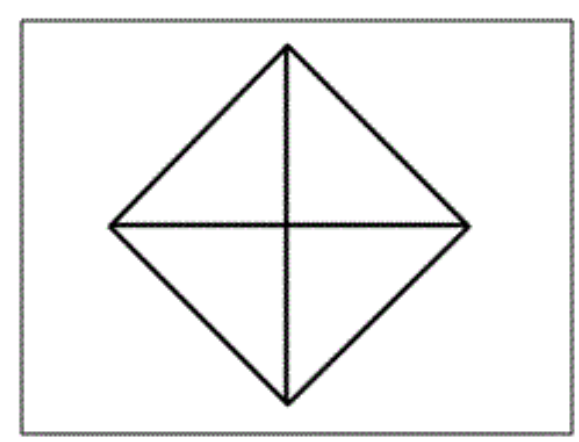

Figure 2: Vickers indentation. Schematic image

The Knoop hardness test was used by Hara and Zero [20] to assess the effect of some beverages - extrinsic acids - with and without calcium on the hardness of enamel after demineralization in different times $(0,5,10,30,60$, and $120 \mathrm{~min})$. The results showed that beverages containing calcium had a reduced capacity to demineralize enamel. In relation to time, after 60 minutes of demineralization the values for the percentage of surface microhardness changes (\%SMHC) were not detected because of the highly demineralized surface caused by some beverages. In this way, the microhardness test is more sensitive for the initial stages of erosion, but has limitations in the analysis of advanced lesions. Therefore, the analysis was complemented using optical profilometry.

Evaluating the influence of erosion and erosion plus abrasion through Knoop microhardness, Rios et al. [8] verified that the enamel blocks subjected to erosion alone presented higher \%SMHC than the blocks subjected to erosion plus toothbrushing. These results showed a possible removal of a softened layer resulting in the exposure of a harder enamel surface in the erosion/abrasion surface. However, only the association of profilometric, microhardness, and scanning electron microscopy images allowed the understanding of the erosive phenomenon and its association with abrasion.

This technique can also be used to test preventive products. Zero et al. [33] evaluated, through surface microhardness, the ability of an experimental dentifrice containing potassium nitrate $(1150 \mathrm{ppm} \mathrm{F})$ to enhance the remineralization of enamel after erosion and whether the substrate remineralized in the presence of the experimental toothpaste is more resistant to subsequent erosive challenges. In this study, test dentifrice (1150 ppm $\mathrm{F}+5 \% \mathrm{KNO}_{3}$; TD) was compared to placebo dentifrice (0 ppm F; PD), dose response control dentifrice (250 ppm F; $\mathrm{DD})$, and clinically tested fluoride dentifrice (1100 ppm F; FD). The results showed that both TD and FD were more effective in enhancing remineralization than $\mathrm{PD}$. TD showed higher resistance against the second erosive challenge than $\mathrm{PD}$ and $\mathrm{DD}$. These results may essentially be attributed to the presence of fluoride in the dentifrice.

Knoop microhardness test also determines the loss of substance by abrasion. By means of the indentations, it is possible to calculate the depth of the indentation. The difference between the depth before and after abrasion provides a direct measurement for the loss of substance $[10,22,24,26,30,31]$. The substance loss $(\Delta \mathrm{d})$ is calculated from the change in indention length $(\Delta \mathrm{l})$ using the geometrical formula: $\Delta \mathrm{d}=0.032772 \Delta \mathrm{l}$. Utilizing the analysis in context, Joiner et al. [30] verified the effect on enamel of three dentifrices with different relative dentine abrasivity (RDA) and relative enamel abrasivity (REA) using an in situ model. The results showed that the dentifrice with the higher REA has a higher level of enamel wear. Unfortunately, measurements of the amount of substance directly removed by an erosive attack could not be performed with this method, since the acid also removes some substance from the body of the indentation and not only from its surrounding, because the main principle of this method is that the body of the indentation is not changed and not removed by the abrasion [36].

The microhardness test has a relatively low cost and can be combined with other measure because it is a non-destructive technique.

\section{Surface Profilometry}

Profilometry is a method to measure enamel or dentin loss caused by erosion and/or abrasion, which can be in contact or non-contact form. In this technique, the samples are covered on one side with a protective tape, creating a so-called reference area, and the other part of the sample remains uncovered to determine the dental wear. This reference area can be a thin layer of composite resin, with no acid etching done and no adhesive system used [7], or it can use nail varnish [15]. Thus, the profilometry measures the difference in height $(\Delta \mathrm{h})$ between the exposed area and the reference. The main advantage of profilometry is the speediness of measurements which take aprroximately on minute per sample [35].

Mechanical profilometry (MP) is widely utilized to evaluate changes in the surface of teeth after abrasion and/or erosion $[6-8,14,15,23,32,39,42,43]$. However, the force applied by the probe on a surface softened by erosion can collapse the area. This effect would be especially strong on samples with relatively severe demineralization, so the measurement of the effect of a soft drink would be exacerbated by contact profilometry [35].

Magalhães et al. [15] assessed by MP the effect of dentifrices with different concentrations of fluoride on dentin subjected to erosion or erosion plus abrasion. This analysis determined that both erosion and erosion plus abrasion wear was higher for placebo dentifrice (0 ppm F) than for the $1100 \mathrm{ppm} \mathrm{F}$ and $5000 \mathrm{ppm} F$ dentifrices, but the fluoride dentifrices did not differ from each other. In this study, it is possible that the lack of difference between fluoridated dentifrices might be explained by the erosive effect that was done for $60 \mathrm{sec}$ four times a day for seven days, promoting a strong demineralization.

The exacerbated values obtained by MP is avoided by using a noncontact profilometry - optical or laser - guided by a computer, which may determine the surface loss with high precision $[9,11,19,20,31]$. However, this equipment is very expensive and it is necessary to have a lot of experience using the system. 
Hara and Zero [20] evaluated the wear occasioned by different acid beverages with or without calcium, as cited previously. The authors used two methods to analyze the micro-structural alteration (microhardness and optical profilometry). In this study, the optical profilometry was the most appropriate method to quantify erosion at advanced stages. The results showed that calcium beverages expect one, did not present any trend for enamel surface loss with increase in demineralization time.

Kielbassa et al. [9] assessed, using laser profilometry, the abrasive effects of toothpastes (low, medium, and high-abrasive paste), acidic gels (fluoride and fluoride-free), and water (control) on sound and demineralized enamel. These authors observed that abrasion was about $50 \%$ less on sound than the demineralized enamel and that the greatest wear was obtained with high-abrasive paste. With the sound and demineralized enamel specimens, the lowest abrasion was observed after brushing with water and with the nonfluoridated acidic gel.

To summarize, profilometry is a fast and non-destructive method, which may be adopted to determine wear with high precision.

\section{Surface Roughness (SR)}

Surface roughness is a method that may be adopted to evaluate the superficial alteration of texture in enamel/dentine after different erosive or abrasive treatments $[23,27,42,44]$. The data of roughness measurement is expressed in Ra values (Roughness average $-\mu \mathrm{m}$ ). Baseline and final roughness are the average of measurements in the samples before and after the treatment, respectively. The roughness is calculated by subtracting the baseline measurements from the posttreatment values [42]. However, this measurement does not allow one to know about the structure loss.

Turssi et al. [42] used a profilometer equipped with a diamond stylus of $2 \mathrm{~mm}$ radius, at a constant speed of $0.05 \mathrm{~mm} / \mathrm{second}$ and with a force of $0.7 \mathrm{mN}$, to evaluate wear depth and roughness of dentifrices (regular, baking soda, tartar control, whitening and distilled water) on enamel exposed to an acid soft drink (Diet Sprite) or distilled water. The authors concluded that there was no significant difference in depth of enamel loss between the sound samples and the specimens subjected to the acidic challenge, and no difference was observed in the dentifrices. However, the surface roughness revealed a significant effect. The exposure to Diet Sprite yielded a higher roughness than did distilled water, and the tartar control dentifrice had a higher surface roughness than those brushed either with distilled water or with the whitening dentifrice.

Similarly, Menezes et al. [23] utilized SR and MP to evaluate the effect of different dentifrices (control, regular, baking soda, whitening, and tartar control) on root dentine previously exposed to erosive challenges. The results obtained with SR and MP was also different, because the roughness assessed the alteration in microstructural surface and not the surface loss.

This technique is little utilized, with scarce recent studies, because it has superficial information. Therefore accurate results, about erosion or erosion plus abrasion, are not obtained; this is not the best method to evaluate preventive products.

\section{Microradiography}

Microradiography is used for quantification of mineral loss based on the attenuation of X-ray irradiation transmitting dental hard tissue.
Microradiographs are obtained with a digital image analyzing system interfaced to a universal microscope and a personal computer. They can be longitudinal when the X-rays are parallel to the direction of the process. The transversal is when the X-rays are perpendicular to the direction of lesion progression [45].

For transverse microradiography (TMR), thin sections are obtained perpendicular to the sample surface and radiographer with a Nickelfiltered $\mathrm{Cu} \mathrm{Ka-line} \mathrm{perpendicular} \mathrm{to} \mathrm{the} \mathrm{cut} \mathrm{surface.} \mathrm{TMR} \mathrm{is} \mathrm{a} \mathrm{valid}$ tool for quantitative assessment of the mineral content as a function of depth from surface. From in-depth profiles, the lesion depth and mineral loss integrated over the entire depth $(\Delta \mathrm{Z})$ of the lesion can be calculated. Lesion depth usually is defined up to the point where the mineral content reaches $95 \%$ of the mineral content of sound enamel or dentin. TMR for erosive mineral loss determination depends on the use of a reference area not subjected to an erosive challenge. However, longitudinal microradiography enables the use of thicker specimens, up to $4 \mathrm{~mm}$ thick, and the changes in mineral content can be calculated using pixel-by-pixel comparison of gray values of radiography after treatment with the gray values of the reference radiograph. The main advantage of microradiography is that the method enables to simultaneously determine surface loss, demineralization, and remineralization of the eroded samples $[36,46]$.

Using transversal microradiography, Kielbassa et al. [21] evaluated the effect of saliva substitutes (Artisial, Glandosane, Oralube, Saliva medae, Mineral water, Biòtene, and Meridol) on the mineral content of pre-demineralized and sound enamel. The data determine that Biotene and Glandosane demineralized the sound enamel; however, all other solutions revealed a significant mineral gain.

Schlueter et al. [16] assessed the effect of $\mathrm{TiF}_{4}$ and $\mathrm{NaF}$ on mineral loss on enamel and dentin using longitudinal microradiography (LMR). The results of this study showed the reduction of enamel and dentine mineral loss by both fluoride solutions. Ganss et al. [12] used the same technique to evaluate the effect of toothpaste fluoridation and intensive fluoridation (toothpaste, mouth-rinse, and gel) in prevention of erosion on enamel and dentine. They observed that intensive fluoridation is effective in preventing enamel and dentine mineral loss on erosive conditions.

\section{Atomic Force Microscopy (AFM) and AFM Nanoindentation}

Recently, the application of atomic force microscopy (AFM), and especially AFM nanoindentation, in biological research has been conducted. AFM provides a powerful tool to investigate the surface morphology of a variety of biological samples with nanometer resolution. There are two types of AFM scanning: tapping mode and contact mode [47]. Tapping mode AFM has been successfully applied to study alterations in enamel. AFM is capable of delivering highresolution images of tooth enamel and, thus, unlike mechanical profilometry, allows quantifying the enamel loss caused by erosion [35]. Figure 3 shows an enamel without erosive/abrasive challenges and Figure 4 shows the micromorphological alteration of enamel after seven days of erosion plus abrasion (immersion in Coke for $5 \mathrm{~min}$, with immediate abrasion for 30 strokes, three times a day).

AFM nanoindentation allows for the measurement of nanomechanical properties, such as surface hardness and reduced elastic modulus, and for indentation depths of less than $100 \mathrm{~nm}$. It has been shown useful for studying the mechanical properties of surface softened enamel $[19,22]$. The nanoindentaion sensibility allows the study of very early stages of enamel erosion [19]. 


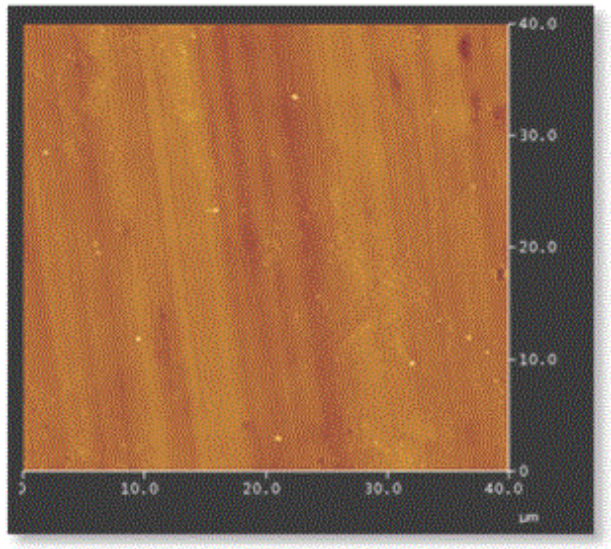

Figure 3: Control

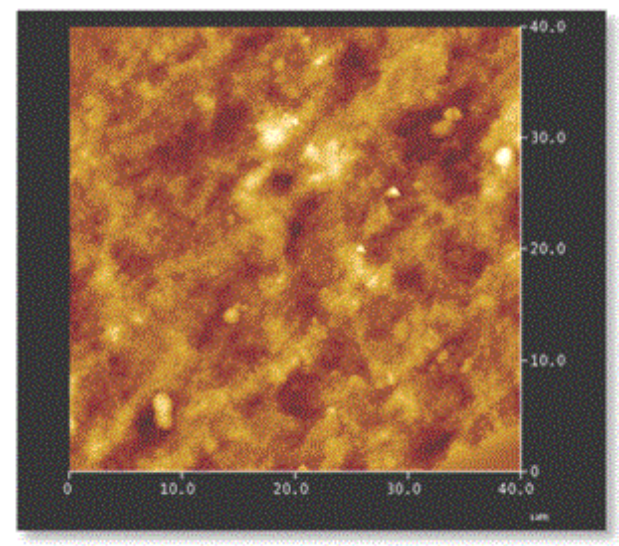

Figure 4: Erosive and abrasive challenges

Lippert et al. [22] investigated the effect of demineralization $(1,2$, or $3 \mathrm{~min}$ ), exposure to artificial saliva and toothbrush abrasion using tapping mode AFM and AFM nanoindentation. The AFM investigations observed that demineralization revealed the prismatic structure of enamel and resulted in a grainy surface structure, while the exposure to artificial saliva led to the deposition of a mineral phase with random orientation. In the images after the brushing treatment, the prismatic structure was still identifiable and appeared smoother than it did prior to the brushing treatment. The AFM nanoindenation investigations showed that toothbrushing of surface softened enamel leads to minor changes in the surface morphology and nanomechanical properties, and the amount of enamel lost due to toothbrushing was independent of the demineralization time.

Barbour et al. [18] investigated the dissolution of human enamel in citric acid solutions over a wide range of $\mathrm{pH}(2.30 \leq \mathrm{pH} \leq 6.30)$ through a nanoindentation study. This analysis was used for the study because it is extremely sensitive to the early stages of enamel dissolution. Using this technique it is possible to distinguish enamel dissolution after short exposure times. The results showed that the enamel has the lowest possible hardness value at a $\mathrm{pH}$ below 2.90.
Barbour et al. [19] assessed by AFM nanoindentaion the nanomechanical properties of enamel exposure to two different noncarbonated soft drinks at $4,25,50$, and $75^{\circ} \mathrm{C}$. The analysis concluded that the nanohardness decreased approximately linearly with the increase of temperature. This technique is utilized because it is more sensitive to changes in the thickness of the enamel softened layer.

In the last five years, AFM and nanoindentation have revolutionized the investigation of food induced enamel erosion. In addition to a fundamental understanding of dental erosion, the results of these studies were applied to develop new soft drinks with reduced erosive potential. They will be useful to in the investigation of erosive challenges $[35,48]$.

\section{Scanning Electron Microscopy (SEM)}

This method only allows subjective and qualitative assessment. Some studies utilize SEM analysis to illustrate the surface subjected to erosive and abrasive challenges on a dental structure $[8,11,25]$. Enamel/dentine samples which are examined with SEM need to be coated with a conductive layer, normally consisting of gold. Furthermore, SEM does not allow quantitative measurements of enamel loss [35].

Vieira et al. [11] evaluated the samples of bovine enamel pretreated with $4 \% \mathrm{TiF} 4, \mathrm{AmF}$, fluoride varnish (FV), fluoride-free varnish, FV, which were subsequently submitted to varnish removal and a control submitted to erosive and/or abrasive challenges. The authors utilized SEM to determine the presence of fluoride or no fluoride varnish after the treatments, showing that samples treated with fluoride varnish had an approximately $2 \mu \mathrm{m}$ varnish layer well attached to the enamel surface, and the sample treated with fluoride-free varnish had a surface layer with a thickness of approximately $1 \mu \mathrm{m}$ partially detached from the enamel. This result was important to show that fluoride varnish is a mechanical barrier permitting the protective effect.

SEM investigation can be used on both polished and unpolished native surfaces only after gold-sputtering. However, it is a destructive analysis, because once covered in gold, the sample cannot be used for any other analysis.

\section{White Light Interferometer (WLI)}

A white light interferometer is a computerized optical microscope that uses interference to produce a topographic image of the surface. Digital WLI images are typically shown as a topographic map where various colors denote different heights for the pixel, as recorded by the WLI software. By subtracting the original image from the image obtained after the experiment, a difference image is created which shows how much enamel had been removed during the erosive challenges. Using WLI, it is also possible to calculate the mean roughness in surface roughness due to the etching of enamel. Therefore, many authors have utilized new techniques to develop the best way to quantify the dental erosion.

Hove et al. [28] compared the protective effect of three fluoride substances $\left(\mathrm{TiF}_{4}, \mathrm{SnF}_{2}\right.$, and $\left.\mathrm{NaF}\right)$ on the development of erosion lesions in human enamel measured by a WLI in vitro. In this study, all the fluoride solutions protected the surface against acid exposure; however, the $\mathrm{TiF}_{4}$ solution provided the best protection. Hove et al. [13] compared the same products through an in situ study. However in this analysis, $\mathrm{NaF}$ had no protective effect and the $\mathrm{TiF}_{4}$ also showed the best protection against an acid attack. These studies show that $\mathrm{TiF}_{4}$ 
forms a protective surface layer or glaze, and this glaze is responsible for the protective effect against acid. These studies have demonstrated that WLI can be used to measure erosion lesions.

\section{Confocal Laser Scanning Microscopy}

Confocal microscopy is a non-destructive, 3-dimensional microscopic topography technique for obtaining high-resolution images. The confocal principle is based on the elimination of stray light from out-of-focus planes by confocal apertures. Images are obtained by scanning over the sample with a spot-size laser beam and recording the light reflected from the in-focus plane. In-depth imaging (tomography) is possible by recording a series of consecutive images either in the optical $x-y$ plane (optical section parallel to the surface) or $\mathrm{x}-\mathrm{z}$ plane (optical section perpendicular to the surface) [49].

Duschner et al. [49] used this technique for investigating the early processes of erosion in dental enamel. According to the confocal images, the enamel surface without a pellicle seemed to be relatively vulnerable to an acidic beverage, and the seven-day in-vitro pellicle seemed to provide a very good protection against the action of the acidic components of the carbonated cola.

In the study conducted by Amaechi et al., [50] the thickness of acquired salivary pellicle within the arches was investigated by the confocal laser microscopy technique. The results showed the pellicle was thinner in the upper anterior palatal surface when compared with the lower anterior lingual surface, and in the upper posterior palatal surface when compared with the lower posterior lingual surface. It has also shown that this variation can determine the sites and severity of erosion within the arches.

Confocal laser scanning microscopy is used in erosion studies [51]. It provides histotomographic images allowing for qualitative assessment and interpretation of hard tissue destruction or mineral dissolution, since light reflection and light scattering of hard tissue samples are influenced by microhistological changes within a tooth sample [36].

\section{Conclusion}

The literature review points out different methods to analyze dental wear, some already well-established and some emerging, ranging from simple to complex techniques. Therefore, the knowledge about these techniques is indispensable to the choice of method to measure dental wear. However, it becomes notable that the effects of erosion on enamel might not be comprehended by a single technique, but requires the use of different tests for complete understanding.

\section{References}

1. Imfeld T (1996) Dental erosion: Definition, classification and links. Eur J Oral Sci 104: 151-155.

2. Bartlett D, Smith BGN (2000) Definition, classification and clinical assessment of attrition, erosion and abrasion of enamel and dentine.

3. Barbour ME, Rees GD (2006) The role of erosion, abrasion and attrition in tooth. J Clin Dent 17: 88-93.

4. Lazarchik DA, Frazier KB (2008) Dental erosion and acid reflux disease: An overview. Gen Dent 57: 151-156

5. Lussi A, Jaeggi T, Zero DT (2004) The role of diet in the aetiology of dental erosion. Caries Res 38: 34-44.

6. Hooper S, West NX, Pickles MJ, Joiner A, Newcombe RG, et al. (2003) Investigation of erosion and abrasion on enamel and dentine: a model in situ using toothpastes of different abrasivity. J Clin Periodontol 30: 802-808.

7. Hara AT, Turssi CP, Teixeira ECN, Serra MC, Cury JA (2003) Abrasive wear on eroded root dentine after different periods of exposure to saliva in situ. Eur J Oral Sci 111: 423-427.

8. Rios D, Honório HM, Magalhães AC, Buzalaf MAR, Palma-Dibb RG, et al. (2006) Influence of toothbrushing on enamel softening and abrasive wear of eroded bovine enamel: an in situ study. Braz Oral Res 20: 148-154.

9. Kielbassa AM, Gillmann L, Zantner C, Meyner-Lueckel H, Hellwig E, et al. (2005) Profilometric and microradiographic studies on the effects of toothpastes and acidic gel abrasivity on sound and demineralized bovine dental enamel. Caries Res 39: 380-386.

10. Lussi A, Jaeggi T, Gerber C, Megert B (2004) Effect of amine/sodium fluoride rinsing on toothbrush abrasion of softened enamel in situ. Caries Res 38: 567-571.

11. Vieira A, Lugtenborg M, Ruben JL, Huysmans MCDNJM (2006) Brushing abrasion of eroded bovine enamel pretreated with topical fluorides. Caries Res 40: 224-230.

12. Ganss C, Klimek J, Brune V, Schürmann A (2004) Effects of two fluoridation measures on erosion progression in human enamel and dentine in situ. Caries Res 38: 561-566.

13. Hove LH, Holme B, Young A, Tveit AB (2008) The protective effect of TiF4, SnF2 and NaF against erosion-like lesions in situ. Caries Res 42: 68-72.

14. Hooper SM, Newcombe RG, Faller R, Eversole S, Addy M, et al. (2007) The protective effects of toothpaste against erosion by orange juice: studies in situ and in vitro. J Dent 35: 476-481.

15. Magalhães AC, Rios D, Moino AL, Wiegand A, Attin T, et al. (2008) Effect of different concentrations of fluoride in dentifrices on dentin erosion subjected or not to abrasion in situ/ ex vivo. Caries Res 42: 112-116.

16. Schlueter N, Ganss C, Mueller U, Klimek J (2007) Effect of titanium tetrafluoride and sodium fluoride on erosion progression in enamel and dentine in vitro. Caries Res 41: 141-145.

17. Vieira A, Ruben JL, Huysmans MCDNJM (2005) Effect of titanium tetrafluoride, amine fluoride and fluoride varnish on enamel erosion in vitro. Caries Res 39: 371-379.

18. Barbour ME, Parker DM, Allen GC, Jandt KD (2003). Human enamel dissolution in citric acid as a function of $\mathrm{pH}$ in the range $2.30 \leq \mathrm{pH} \leq$ 6.30 - a nanoindentation study. Eur J Oral Sci 111: 258-262.

19. Barbour ME, Finke M, Parker DM, Hugles JA, Allen GC, et al. (2006) The relationship between enamel softening and erosion caused by soft drinks at a range of temperatures. J Dent 34: 207-213.

20. Hara AT, Zero DT (2008) Analysis of the erosive potential of calciumcontaining acidic beverages. Eur J Oral Sci 116: 60-65.

21. Kielbassa AM, Shohadai SP, Schulte-mönting J (2000) Effect of saliva substitutes on mineral content of demineralized and sound dental enamel. Support Care Cancer 9: 40-47.

22. Lippert F, Parker DM, Jandt KD (2004) Toothbrush abrasion of surface softened enamel studied with tapping mode AFM and AFM nanoindentation. Caries Res 38: 464-472.

23. Menezes M, Turssi CP, Hara AT, Messias DCF, Serra MC (2004) Abrasion of eroded root dentine brushed with different toothpastes. Clin Oral Invest 8: 151-155.

24. Philpotts CJ, Weader E, Joiner A (2005) The measurement in vitro of enamel and dentine wear by toothpastes of different abrasivity. Int Dent J 55: 183-187.

25. Shellis RP, Finke M, Eisenburger M, Parker DM, Addy M (2005) Relationship between enamel erosion and liquid flow rate. Eur J Oral Sci 113: 232-238.

26. Wiegand A, Wegehaupt F, Werner C, Attin T (2007) Susceptibility of acid-softened enamel to mechanical wear - ultrasonication versus toothbrushing abrasion. Caries Res 41: 56-60. 
Citation: Passos VF, Santiago SL (2014) Methodologies to Analyze the Micromorphological Alterations of Enamel Subjected to Abrasion/ Erosion. Dentistry 4: 255. doi:10.4172/2161-1122.1000255

Page 7 of 7

27. Worschech CC, Rodrigues JA, Martins LR, Ambrosano GM (2006) Brushing effect of abrasive dentifrices during at-home bleaching with $10 \%$ carbamide peroxide on enamel surface roughness. J Contemp Dent Pract 7: 1-9.

28. Hove L, Holme B, Øgaard B, Willumsen T, Tveit AB (2006) The protective effect of $\mathrm{TiF} 4, \mathrm{SnF} 2$ and $\mathrm{NaF}$ on erosion of enamel by hydrochloric acid in vitro measured by white light interferometry. Caries Res 40: 440-443.

29. West, NX, Jandt KD (2000) Methodologies and instrumentation to measure tooth wear: future perspectives.

30. Joiner A, Pickles MJ, Tanner C, Weader E, Doyle P (2004) An in situ model study the toothpaste abrasion of enamel. J Clin Periodontol 31: 434-438.

31. Pickles MJ, Joiner A, Weader E, Cooper YL, Cox TF (2005) Abrasion of human enamel and dentine caused by toothpastes of differing abrasivity determined using an in situ wear model. Int Dent J 55: 188-193.

32. Turssi CP, Faraoni JJ, Rodrigues Jr AL, Serra MC (2004) An in situ investigation into the abrasion of eroded dental hard tissues by a whitening dentifrice. Caries Res 38: 473-477.

33. Zero DT, Hara AT, Kelly SA, González-Cabezas C (2006) Evaluation of a desensitizing test dentifrice using an in situ erosion remineralization model. J Clin Dent 17:112-116.

34. Low IM, Alhuthali A (2008) In-situ monitoring of dental erosion in tooth enamel when exposed to soft drinks. Mater Sci Eng.

35. Jandt KD (2006) Probing the future in functional soft drinks on the nanometer scale - towards tooth friendly soft drinks. Trends in Food Science \& Technology 17: 263-271.

36. Attin $\mathrm{T}$ (2006) Methods for assessment of dental erosion. Karger, Switzerland.

37. Passos VF, Melo MA, Silva FF, Rodrigues LK, Santiago SL (2014) Effects of Diode Laser Therapy and Stannous Fluoride on Dentin Resistance Under Different Erosive Acid Attacks. Photomed Laser Surg 32: 146-151.

38. Passos VF, Melo MA, Vasconcellos AA, Rodrigues LK, Santiago SL (2013) Comparison of methods for quantifying dental wear caused by erosion and abrasion. Microsc Res Tech 76: 178-183.

39. Yamashita JM, Torres NM, Moura-Grec PG, Marsicano JA, Sales-Peres A, et al. (2013) Role of arginine and fluoride in the prevention of eroded enamel: an in vitro model. Aust Dent J 58: 478-482.
40. Eygen IV, Vannet BV, Wehrbein H (2005) Influence of a soft drink with low $\mathrm{pH}$ on enamel surfaces: an in vitro study. Am J Orthod Dentofacial Orthop 128: 372-377.

41. Elias CN, Lopes HP (2001) Mechanical tests. (1stedn), Artes Médicas, São Paulo.

42. Turssi CP, Messias DCF, Menezes M, Hara AT, Serra MC (2005) Role of dentifrices on abrasion of enamel exposed to an acidic drink. Am J Dent 18: 251-255.

43. West NX, Hooper SM, O'Sullivan D, Hughes N, North M, et al. (2012) In situ randomised trial investigating abrasive effects of two desensitising toothpastes on dentine with acidic challenge prior to brushing. J Dent 40: 77-85.

44. Ferreira MC, Ramos-Jorge ML, Delbem AC, Vieirac Rde S (2013) Effect of Toothpastes with Different Abrasives on Eroded Human Enamel: An in situ/ex vivo Study. Open Dent J 30: 132-139.

45. Thomas RZ, Ruben JL, Vries J, Ten Bosch JJ, Huysmans MC (2006) Transversal wavelength-independent microradiography, a method for monitoring caries lesions over time, validated with transversal microradiography. Caries Res 40: 281-291.

46. Mathews MS, Amaechi BT, Ramalingam K, Ccahuana-Vasquez RA, Chedjieu IP, et al. (2012) In situ remineralisation of eroded enamel lesions by $\mathrm{NaF}$ rinses. Arch Oral Biol 57: 525-530.

47. Santos NC, Castanho MARB (2004) An overwiew of the biophysical applications of atomic force microscopy. Biophys Chem 107: 133-149.

48. Wang CP, Huang SB, Liu Y, Li JY, Yu HY (2014) The CPP-ACP relieved enamel erosion from a carbonated soft beverage: An in vitro AFM and XRD study. Arch Oral Biol 59: 277-282.

49. Duschner H, Götz H, Walker R, Lussi A (2000) Erosion of dental enamel visualized by confocal laser scanning microscopy.

50. Amaechi BT, Higham SM, Edgar WM, Milosevic A (1999) Thickness of acquired salivary pellicle as a determinant of the sites of dental erosion. J Dent Res 78: 1821-1828.

51. Paepegaey AM, Barker ML, Bartlett DW, Mistry M, West NX, et al. (2013) Measuring enamel erosion: a comparative study of contact profilometry, non-contact profilometry and confocal laser scanning microscopy. Dent Mater 29: 1265-1267. 